$\pm N / N$

Global Journals In

(5)

En

2

\title{
Effects of Correlation between the Error Term and Autocorrelation on Some Estimators in a System of Regression Equations
}

By Olanrewaju, Samuel Olayemi

University of Abuja

Abstract- Seemingly unrelated regression model developed to handle the problem of correlation among the error terms of a system of the regression equations is still not without a challenge, where each regression equation must satisfy the assumptions of the standard regression model. When dealing with time-series data, some of these assumptions, especially that of independence of the regressors and error terms leading to multicollinearity and autocorrelation respectively, are often violated. This study examined the effects of correlation between the error terms and autocorrelation on the performance of seven estimators and identify the estimator that yields the most preferred estimates under the separate or joint influence of the two correlation effects considered by the researcher. A two-equation model was considered, in which the first equation had multicollinearity and autocorrelation problems while the second one had no correlation problem. The error terms of the two equations were also correlated. The levels of correlation between the error terms and autocorrelation were specified between -1 and +1 at interval of 0.2 except when it approached unity.

GJSFR-F Classification: MSC 2010: 62M10

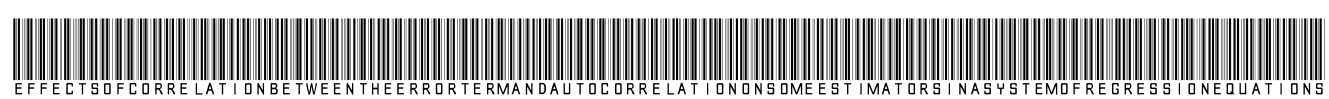

Strictly as per the compliance and regulations of:

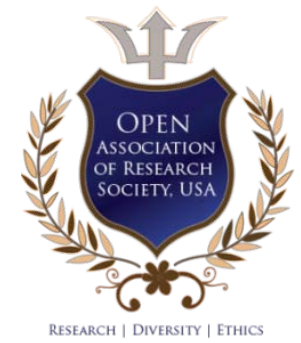

(C) 2020. Olanrewaju, Samuel Olayemi. This is a research/review paper, distributed under the terms of the Creative Commons Attribution-Noncommercial 3.0 Unported License http://creativecommons.org/licenses/by-nc/3.0/), permitting all non commercial use, distribution, and reproduction in any medium, provided the original work is properly cited. 

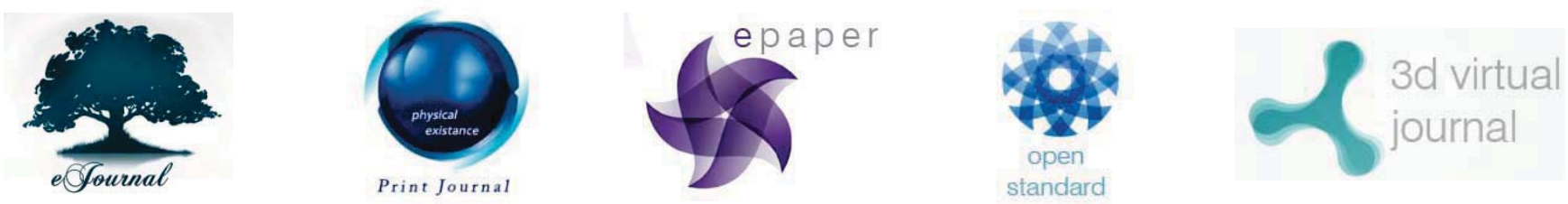

\section{Effects of Correlation between the Error Term and Autocorrelation on Some Estimators in a System of Regression Equations}

Olanrewaju, Samuel Olayemi

Abstract-Seemingly unrelated regression model developed to handle the problem of correlation among the error terms of a system of the regression equations is still not without a challenge, where each regression equation must satisfy the assumptions of the standard regression model. When dealing with time-series data, some of these assumptions, especially that of independence of the regressors and error terms leading to multicollinearity and autocorrelation respectively, are often violated. This study examined the effects of correlation between the error terms and autocorrelation on the performance of seven estimators and identify the estimator that yields the most preferred estimates under the separate or joint influence of the two correlation effects considered by the researcher. A twoequation model was considered, in which the first equation had multicollinearity and autocorrelation problems while the second one had no correlation problem. The error terms of the two equations were also correlated. The levels of correlation between the error terms and autocorrelation were specified between -1 and +1 at interval of 0.2 except when it approached unity. A Monte Carlo experiment of 1000 trials was carried out at five levels of sample sizes 20,30, 50, 100, and 250 at two runs. The seven estimation methods namely; Ordinary Least Squares (OLS), Cochran - Orcutt (CORC), Maximum Likelihood Estimator (MLE), Multivariate Regression, Full Information Maximum Likelihood (FIML), Seemingly Unrelated Regression Model (SUR), and Three-Stage Least Squares (3SLS). Their performances were examined by subjecting the results obtained from each finite property of the estimators into a multi-factor analysis of variance model. The significant factors were further checked using their estimated marginal means and the Least Significant Difference (LSD) methodology to determine the best estimator. The findings generally show that the estimator of MLE is preferred to estimate all the parameters of the model in the presence of correlation between the error terms and autocorrelation at all the sample sizes. This study has applications in areas such as Economics, Econometrics, Social Sciences, Agricultural Economics, and some other fields where the correlation between the error terms and autocorrelation problems can be encountered.

\section{INTRODUCTION}

The seemingly unrelated regression (SUR) model is common in the Econometric literature (Zellner, 1962; Srivastava and Giles, 1987; Greene, 2003) but is less known elsewhere, its benefits have been explored by several authors, and more recently the SUR model is being applied in Agricultural Economics (O' Dorell et al. 1999), Wilde et al. (1999). Its application in the natural and medical sciences is likely to increase once scientists in the disciplines are exposing to its potential.

The SUR estimation procedures which enable an efficient joint estimation of all the regression parameters were first reported by Zellner (1962), which involves the 
application of Aitken's Generalised Least Squares (AGLS) (Aitken 1935, Powell 1965) to the whole system of equations. Zellner (1962 \& 1963), submitted that the joint estimation procedure of SUR is more efficient than the equation-by-equation estimation procedure of the Ordinary Least Square (OLS). The gain in efficiency would be magnified if the contemporaneous correlation between each pair of the disturbances in the SUR system of equations is very high and explanatory variables (covariates) in different equations are uncorrelated. In other words, the efficiency in the SUR formulation increases, the more the correlation between error vectors differs from zero, and the closer the explanatory variables for each response are to being uncorrelated.

David (1999), in his work on test for auto correlated errors which are generalized to cover systems of equations and the properties of 18 versions of the test are studied using Monte Carlo methods. However, the size and power properties of all tests deteriorate sharply as the number of equations increases, the system becomes more dynamic, the exogenous variables become more auto correlated, and the sample size decreases. This performance has, in general, an unknown degree since the interaction amongst these factors does not permit a predictive summary, as might be hoped for by response surface-type approaches.

Unger et al. (2009), in their work, developed a regression model for use with ensemble forecasts. Ensemble members are assumed to represent a set of equally likely solutions, one of which will best fit the observation. If standard linear regression assumptions apply to the best member, then a regression relationship can be derived between the full ensemble and the observation without explicitly identifying the best member for each case. The ensemble regression equation is equivalent to linear regression between the ensemble mean and the observed data, but is applied to each member of the ensemble. The "best member" error variance is defined in terms of the correlation between the ensemble mean and the observations, their respective variances, and the ensemble spread.

\section{a) Methods of Parameter Estimation of the Linear Model with Auto correlated Errors}

The GLS and the OLS methods are the two methods that can be used to estimate the parameters of the linear model in the presence of auto correlated error. Since the later suffers efficiency, the former is used to improve this efficiency. However, Chipman (1979), Kramer (1980), Kleiber (2001), Olanrewaju S.O. (2017), among many others, have observed that the efficiency of the OLS estimator in a linear regression containing an auto correlated error term depends largely on the structure of X used. The GLS method requires that $\Omega$, and in particular, $\rho$ is known before the parameters can be estimated. Thus, in a linear model with an auto correlated error term

$$
\begin{aligned}
\tilde{\beta}_{(\mathrm{GLS})} & =\left(X^{1} \Omega^{-1} X\right)^{-1} X^{1} \Omega^{-1} Y \\
\mathrm{~V}\left(\tilde{\beta}_{(\mathrm{GLS})}\right) & =\sigma^{2}\left(X^{1} \Omega^{-1} X\right)^{-1}
\end{aligned}
$$

Where

$$
E\left(U U^{\prime}\right)=\sigma^{2} \Omega=\sigma^{2}\left[\begin{array}{cccccc}
1 & \rho & \rho^{2} & \cdots & \rho^{n-2} & \rho^{n-1} \\
\rho & 1 & \rho & \cdots & \rho^{n-3} & \rho^{n-2} \\
\rho^{2} & \rho & 1 & \cdots & \rho^{n-4} & \rho^{n-3} \\
\vdots & \vdots & \vdots & \ddots & \vdots & \vdots \\
\rho^{n-2} & \rho^{n-3} & \rho^{n-4} & \cdots & 1 & \rho \\
\rho^{n-1} & \rho^{n-2} & \rho^{n-3} & \cdots & \rho & 1
\end{array}\right]
$$


And

$$
\sigma^{2}=\sigma_{u}^{2}=\frac{\sigma_{\varepsilon}^{2}}{\left(1-\rho^{2}\right)}
$$

And the inverse of $\Omega$ is

$$
\Omega^{-1}=\frac{1}{1-\rho^{2}}\left[\begin{array}{cccccc}
1 & -\rho & 0 & \cdots & 0 & 0 \\
-\rho & 1+\rho^{2} & -\rho & \cdots & 0 & 0 \\
0 & -\rho & 1+\rho^{2} & \cdots & 0 & 0 \\
\vdots & \vdots & \vdots & \ddots & \vdots & \vdots \\
0 & 0 & 0 & \cdots & 1+\rho^{2} & -\rho \\
0 & 0 & 0 & \cdots & -\rho & 1
\end{array}\right]
$$

We now search for a suitable transformation matrix $P^{*}$, as discussed in section 2.1.

If we consider an $(\mathrm{n}-1) \mathrm{x} \mathrm{n}$ matrix $P^{*}$ defined by

$$
P^{*}=\left[\begin{array}{cccccc}
-\rho & 1 & 0 & \cdots & 0 & 0 \\
0 & -\rho & 1 & \cdots & 0 & 0 \\
0 & 0 & -\rho & \cdots & 0 & 0 \\
\vdots & \vdots & \vdots & \ddots & \vdots & \vdots \\
0 & 0 & 0 & \cdots & 0 & 0 \\
0 & 0 & 0 & \cdots & -\rho & 1
\end{array}\right]_{(\mathrm{n}-1) \times \mathrm{n}}
$$

Multiplying then shows that $P^{* 1} P^{*}$ gives an $\mathrm{n} \times \mathrm{n}$ matrix which apart from a proportional constant is identical with $\Omega^{-1}$ except for the first elements in the leading diagonal, which is $\rho^{2}$ rather than unity.

Now if we consider an $\mathrm{n} \times \mathrm{n}$ matrix $\mathrm{P}$ obtained from $P^{*}$ by adding a new row to the first row with $\sqrt{1-\rho^{2}}$ in the first position and zero elsewhere, that is

$$
\mathrm{P}=\left[\begin{array}{cccccc}
\left(1-\rho^{2}\right)^{\frac{1}{2}} & 0 & 0 & \cdots & 0 & 0 \\
-\rho & 1 & 0 & \cdots & 0 & 0 \\
0 & -\rho & 1 & \cdots & 0 & 0 \\
\vdots & \vdots & \vdots & \ddots & \vdots & \vdots \\
\vdots & \vdots & \vdots & \cdots & \vdots & \vdots \\
0 & 0 & 0 & \cdots & -\rho & 1
\end{array}\right]_{(\mathrm{nxn})}
$$

Multiplying shows that $P^{1} P=\left(1-\rho^{2}\right) \Omega^{-1}$. The difference between $P^{*}$ and $\mathrm{P}$ lies only in the treatment of the first sample observation, $P^{*}$ is much easier to use, provided we are prepared to lose information on the first observation. However, when $\mathrm{n}$ is large, the difference is negligible, but in a small samples such as in this study, the difference can be large.

If $\Omega$ or more precisely, $\rho$ is known, the GLS estimation can be achieved by applying the OLS via the transformation matrix $P^{*}$ and $P$ above. However, this is not often the case; we resort to estimating $\Omega$ by $\Omega$ to have feasible Generalized Least Squares Estimator. This estimator becomes feasible when $\mathrm{P}$ is replaced by a consistent estimator $\rho$ (Formby et al. 1988).

b) Notations:

* : Computed $\mathrm{F}$ value is significant at $\alpha=0.01$

** : Computed $\mathrm{F}$ value is significant at $\alpha=0.05$ 
CR-: Correlation between the error terms

RE-: Autocorrelation

BB-: Bias

AB-: Absolute Bias

MB-: Mean Square Error

VB-: Variance

OLS-: Ordinary Least Squares

COCR-: Cochrane - Orcutt (Generalized Least Squares)

MLE-: Maximum Likelihood Estimator

MULTIREG-: Multivariate Regression

FIML-: Full Information Maximum Likelihood

SUR -: Seemingly Unrelated Regression

3SLS -: Three Stage Least Squares

M-: Method

\section{il. The Monte - Carlo Approach}

Monte-Carlos is a mathematical technique based on experiment for evaluation and estimation of problems which are intractable by probabilistic or deterministic approach. By probabilistic Monte-Carlo experiment, random numbers are observed and chosen in such a way that they directly simulate the physical random process of the original problem. The desired solutions from the behavior of these random numbers are then inferred. The idea of a Monte-Carlo approach to deterministic problems is to exploit the strength of theoretical Mathematics, which cannot be solved by theoretical means but now being solved by a numerical approach.

The Monte-Carlo approach has been found useful to investigate the small (finite) sample properties of these estimators. The use of this approach is because real-life observation on economic variables is in most cases, plagued by one or all of the problems of nonspherical disturbances and measurement and misspecification errors. By this approach, data sets and stochastic terms are generated, which are free from all the problems listed above and, therefore, it can be regarded as data obtained from a controlled laboratory experiments.

In a Monte-Carlo experiment, the experimenter artificially sets up a system (model) and specifies the distribution of the independent variables alongside with the values of the model parameters. Those values are then generated for the error term and the independent variables as specified for a specified sample size. By using those generated values and the parameter values, the value of the dependent variable is thus determined. Next is to treat the generated data as if they are real-life data by estimating the parameters of the model via the estimation methods (estimators). This process of generating values for the disturbance term, independent variables, and estimating the parameters of the model is then replicated a large number of times. The experimenter then builds up empirical distributions of the parameter estimates, which are then used to evaluate the performance of the estimators in estimating the parameter values.

The Monte - Carlo studies can be designed generally by using the following summarized five steps as given below:

(a) The researcher specifies a model and assigns specific numeric values as in parameters. The assigned values are assumed to be the real values of the parameter.

(b) The distribution of error terms is also specified by the researcher. 
(c) He uses the distribution of U's with the random drawings from it to obtain different values for the error terms.

(d) The experimenter now selects or generates values for the regressors (X's) depending on the specifications of the model.

(e) The researcher obtains or generates values for the dependent variable using the real values of the regressors and the error terms. (Olanrewaju et al. 2017)

The five steps mentioned above are repeated several times, say $R$, to have $R$ replications.

Thus, the experimenter obtains an estimate of the model parameters for each replication, treating the generated data as real-life data.

(i) Seven estimation methods under consideration

(ii) Different number of replication (replication of 1000 in this context)

(iii) Different sample sizes of 20, 30, 50, 100, and 250 as used in this study. (Olanrewaju et al. 2017)

\section{ili. The Model Formulation}

The System of regression equations used in this research work as proposed by Olanrewaju S.O. (2013) is given as:

$$
y_{1 t}=\beta_{01}+\beta_{11} x_{1 t}+\beta_{12} x_{2 t}+u_{1 t}
$$

where,

$$
\begin{aligned}
& u_{1 t}=\rho u_{1(t-1)}+e_{1 t}, e_{1 t} \approx\left(0, \sigma^{2}\right) . \\
& y_{2 t}=\beta_{02}+\beta_{21} x_{1 t}+\beta_{22} x_{3 t}+u_{2 t}, u_{2 t} \approx N\left(0, \sigma^{2}\right)
\end{aligned}
$$

Note: (1) Multicollinearity exists between $\mathrm{X}_{1}$ and $\mathrm{X}_{2}$ in equation (3.1)

(2) Autocorrelation exists in equation (3.1)

(3) There is a correlation between $U_{1}$ and $U_{2}$ of the two equations

(4) There is no correlation between $\mathrm{X}_{1}$ and $\mathrm{X}_{3}$ in equation (3.2). Thus, equation (3.2) appears as a control equation.

a) The Equation used for generating values in the simulation

The equation used for generating values of the variables in the simulation study as proposed by Ayinde K. (2007) is given below:

Suppose, $W_{i} \sim N\left(\mu, \sigma_{i}^{2}\right) \quad i=1,2$. If these variables are correlated, then, $\mathrm{W}_{1}$ and $\mathrm{W}_{2}$ can be generated with the following equations:

$$
\begin{aligned}
& W_{1}=\mu_{1}+\sigma_{1} z_{1} \\
& W_{2}=\mu_{2}+\rho \sigma_{2} z_{1}+\sigma_{2} z_{2} \sqrt{1-\rho^{2}}
\end{aligned}
$$

Where $\mathrm{Z}_{\mathrm{i}}^{\sim} \mathrm{N}(0,1) \quad \mathrm{i}=1,2$ and $|\rho|<1$ is the value of the correlation between the two variables.

\section{b) Other Specifications}

1. Sample Size(n) of 20, 30, 50, 100 and 250 were used in the simulation

2. The following levels were used for the correlations studied:

a. Autocorrelation(RE): $-0.99,-0.9,-0.8,-0.6,-0.4,-0.2,0,0.2,0.4,0.6,0.8,0.9,0.99$ 
b. Correlation between error term (CR) : $-0.99,-0.9,-0.8,-0.6,-0.4,-0.2,0,0.2,0.4,0.6$, $0.8,0.9,0.99$

c. Replication (RR) : we make use of 1000 replications

d. Two RUNS were done for the simulations which were averaged at analysis stage.

c) Criteria for comparison

The evaluation and comparison of the seven (7) estimators considered in this study were examined using the finite sampling properties of estimators, which include Bias (BB), Absolute Bias (AB), Variance (VB), and the Mean Square Error (MB) criteria.

Mathematically, for any estimator $\hat{\beta}_{i}$ of $\beta_{i}$ of the models (3.1) \& (3.2)
(i) $\hat{\beta}_{i}=\frac{1}{R} \sum_{j=1}^{R} \hat{\beta}_{i j}$
(ii) $\operatorname{Bias}\left(\hat{\beta}_{i}\right)=\frac{1}{R} \sum_{j=1}^{R}\left(\hat{\beta}_{i j}-\beta_{j}\right)=\hat{\beta}_{i}-\beta_{i}$
(iii) $A B\left(\hat{\beta}_{i}\right)=\frac{1}{R} \sum_{j=1}^{R}\left|\hat{\beta}_{i j}-\beta_{j}\right|$
(iv) $\operatorname{Var}\left(\hat{\beta}_{i}\right)=\frac{1}{R} \sum_{j=1}^{R}\left(\hat{\beta}_{i j}-\hat{\beta}_{i}\right)^{2}$

(v) $\operatorname{MSE}\left(\hat{\beta}_{i}\right)=\frac{1}{R} \sum_{j=1}^{R}\left(\hat{\beta}_{i j}-\beta_{i}\right)^{2}$, for $\mathrm{i}=0,1,2$ and $\mathrm{j}=1,2, \ldots, \mathrm{R}$.

Using a computer program which was written with TSP software package to estimate all the model parameters and the criteria, the performances of seven estimation methods; Ordinary Least Squares (OLS), Cochran - Orcutt (COCR), Maximum Likelihood Estimator (MLE), Multivariate Regression, Full Information Maximum Likelihood (FIML), Seemingly Unrelated Regression (SUR) and Three-Stage Least Squares (3SLS) were examined by subjecting the results obtained from each finite properties of the estimators into a multi-factor analysis of variance model. Consequently, the highest order significant interaction effect, which has a "method" as a factor, is further examined using the Least Significance Difference (LSD) test. The estimated marginal mean of the factor was investigated out at a particular combination of levels of the correlations in which estimators were preferred if the marginal mean is the smallest.

\section{Analysis and Results}

The summary of results from the Analysis of variance tables of the criteria showing the effect of the estimators, the correlation between the error term and autocorrelation on $\beta_{\mathrm{i}}$ are presented in Table 1 below. 
Table 1: ANOVA for a sample size of 20

\begin{tabular}{|c|c|c|c|c|c|c|c|c|}
\hline \multirow{2}{*}{ s.no. } & \multirow{2}{*}{ SOV } & \multirow{2}{*}{ EQN } & \multirow{2}{*}{$\boldsymbol{\beta}_{\mathrm{i}}$} & \multirow{2}{*}{ df } & \multicolumn{4}{|c|}{ TYPE III SUM OF SQUARES } \\
\hline & & & & & Bias & Absolute Bias & Variance & Mean Square \\
\hline \multirow[t]{48}{*}{20} & \multirow[t]{6}{*}{ RE } & \multirow[t]{3}{*}{1} & $\beta 01$ & 12 & $892.446^{\star \star \star}$ & 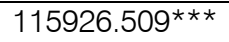 & $2445822.237^{\star \star \star}$ & $3951716.298^{\star \star \star}$ \\
\hline & & & $\beta 11$ & 12 & $.029 * \star \star$ & $32.515^{\star \star \star}$ & $95.927^{\star \star \star}$ & $96.084^{\star \star \star}$ \\
\hline & & & $\beta 21$ & 12 & .012 & $24.373^{\star \star \star}$ & $23.509 * \star \star$ & $87.017^{\star \star \star}$ \\
\hline & & \multirow[t]{3}{*}{2} & $\beta 02$ & 12 & .112 & $103.206^{\star \star \star}$ & $122116.658^{\star \star \star}$ & $128548.527^{\star \star \star}$ \\
\hline & & & $\beta 12$ & 12 & .063 & $.628^{\star \star \star}$ & $.093^{\star \star \star}$ & $.091^{\star \star \star}$ \\
\hline & & & $\beta 22$ & 12 & $.132^{\star \star \star}$ & $.605^{\star \star \star}$ & $.113^{\star \star \star}$ & $.125^{\star \star \star}$ \\
\hline & \multirow[t]{6}{*}{ CR } & \multirow[t]{3}{*}{1} & $\beta 01$ & 12 & .670 & .003 & .003 & .005 \\
\hline & & & $\beta 11$ & 12 & .001 & $6.016 \mathrm{E}-5$ & 8.532E-5 & 8.897E-5 \\
\hline & & & $\beta 21$ & 12 & $7.468^{\star \star \star}$ & $3.807^{\star \star \star}$ & $3.176^{\star \star \star}$ & $5.004^{\star \star \star}$ \\
\hline & & \multirow[t]{3}{*}{2} & $\beta 02$ & 12 & 3.519 & $45.130^{\star \star \star}$ & $113879.706^{\star \star *}$ & $119769.347^{\star \star \star}$ \\
\hline & & & $\beta 12$ & 12 & $.513^{\star \star \star}$ & .032 & $.224^{\star \star \star}$ & $.032^{\star \star \star}$ \\
\hline & & & $\beta 22$ & 12 & $3.006^{\star \star \star}$ & $.404^{\star \star \star}$ & $.139 * \star \star$ & $.011^{\star \star \star}$ \\
\hline & \multirow[t]{6}{*}{ M } & \multirow[t]{3}{*}{1} & $\beta 01$ & 6 & $315.786^{\star \star \star}$ & $83483.317^{\star \star \star}$ & $4080093.223^{\star \star \star}$ & $6466311.896^{\star \star \star}$ \\
\hline & & & $\beta 11$ & 6 & .000 & $4.612^{\star \star \star}$ & $5.977^{\star \star \star *}$ & $5.990^{\star \star \star}$ \\
\hline & & & $\beta 21$ & 6 & .007 & $5.564^{\star \star \star}$ & $2.320 * \star \star$ & $9.779 * \star \star$ \\
\hline & & \multirow[t]{3}{*}{2} & $\beta 02$ & 6 & .042 & $45.091 * \star \star$ & $232859.705^{\star \star \star}$ & 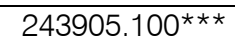 \\
\hline & & & $\beta 12$ & 6 & $.476^{\star \star \star}$ & $.141^{\star \star \star}$ & $.002^{\star \star \star}$ & $.006^{\star \star \star}$ \\
\hline & & & $\beta 22$ & 6 & $.086^{\star \star \star}$ & $2.096^{\star \star \star}$ & $.361^{* \star \star}$ & $.391^{\star \star \star}$ \\
\hline & \multirow[t]{6}{*}{$\mathrm{RE}^{\star} \mathrm{CP}$} & & $\beta 01$ & 144 & .458 & .026 & .021 & .037 \\
\hline & & & $\beta 11$ & 144 & .001 & .000 & .001 & .001 \\
\hline & & & $\beta 21$ & 144 & 5.046 & 1.759 & $7.126^{\star * \star}$ & $19.761 * *$ \\
\hline & & & $\beta 02$ & 144 & 5.506 & $195.745^{\star \star \star}$ & $360069.375^{\star \star \star}$ & $378405.077^{\star \star \star}$ \\
\hline & & & $\beta 12$ & 144 & .048 & $.423^{\star \star \star}$ & $.054^{\star \star \star}$ & $.052^{\star \star *}$ \\
\hline & & & $\beta 22$ & 144 & .019 & $256^{\star \star \star}$ & $.053^{* \star *}$ & $.052^{\star \star \star}$ \\
\hline & RE*M & 1 & $\beta 01$ & 72 & $5540.631^{\star \star *}$ & $454326.369 * * \star$ & $1.038 \mathrm{E} 7 * \star \star$ & $1.557 \mathrm{E} 7 * \star \star$ \\
\hline & & & $\beta 11$ & 72 & .011 & $15.816^{\star \star \star}$ & $40.207^{\star \star \star}$ & $40.276^{\star \star \star}$ \\
\hline & & & $\beta 21$ & 72 & .014 & $15.506^{\star * *}$ & $13.080^{\star * *}$ & $56.497^{\star \star \star}$ \\
\hline & & 2 & $\beta 02$ & 72 & 675 & $199.404^{\star \star \star}$ & $716966.573^{\star \star \star}$ & $755012.778^{\star \star \star}$ \\
\hline & & & $\beta 12$ & 72 & 201 & .078 & $.007^{* *}$ & .007 \\
\hline & & & $\beta 22$ & 72 & $.116^{\star \star \star}$ & $529 * \star \star$ & $131^{* \star *}$ & $134^{\star \star \star}$ \\
\hline & $\mathrm{CR}^{\star} \mathrm{M}$ & 1 & $\beta 01$ & 72 & .515 & .002 & .002 & .004 \\
\hline & & & $\beta 11$ & 72 & .001 & 4.520E-5 & $6.406 \mathrm{E}-5$ & $6.680 \mathrm{E}-5$ \\
\hline & & & $\beta 21$ & 72 & 5.943 & $2.889^{* * *}$ & $2.473^{\star *}$ & 3.902 \\
\hline & & 2 & $\beta 02$ & 72 & 3.940 & $196.384^{\star * \star}$ & $683436.471^{\star \star \star}$ & $721549.650^{\star \star \star}$ \\
\hline & & & $\beta 12$ & 72 & .243 & $.407^{\star \star \star}$ & .004 & $.022^{\star \star \star}$ \\
\hline & & & $\beta 22$ & 72 & $.148^{\star * \star}$ & $1.340^{\star * *}$ & $289 * * \star$ & $246^{\star \star \star}$ \\
\hline & $\mathrm{RE}^{\star} \mathrm{CR}$ & 1 & $\beta 01$ & 864 & .348 & .020 & .017 & .030 \\
\hline & M & & $\beta 11$ & 864 & .001 & .000 & .000 & .000 \\
\hline & & & $\beta 21$ & 864 & 3.917 & 1.358 & 5.731 & 15.895 \\
\hline & & 2 & $\beta 02$ & 864 & 33.150 & $884.547^{* \star \star}$ & $2141981.317^{\star \star \star}$ & $2251208.104^{* \star *}$ \\
\hline & & & $\beta 12$ & 864 & .072 & .059 & .006 & .005 \\
\hline & & & $\beta 22$ & 864 & .082 & .433 & .102 & .103 \\
\hline & ERROค & 1 & $\beta 01$ & 1183 & 3595.810 & 8759.488 & 8834975.252 & 8871627.167 \\
\hline & & & $\beta 11$ & 1183 & .245 & 11.841 & 50.548 & 50.564 \\
\hline & & & $\beta 21$ & 1183 & 84.299 & 23.465 & 28.185 & 128.394 \\
\hline & & 2 & $\beta 02$ & 1183 & 214.134 & 135.089 & 1384793.426 & 1438377.807 \\
\hline & & & $\beta 12$ & 1183 & 16.754 & 2.534 & .089 & 150 \\
\hline & & & $\beta 22$ & 1183 & .659 & 1.140 & 197 & .256 \\
\hline & TOTAL & 1 & $\beta 01$ & 2365 & 10346.814 & 662542.071 & $2.575 \mathrm{E} 7$ & $3.487 \mathrm{E} 7$ \\
\hline & & & $\beta 11$ & 2365 & .288 & 64.783 & 192.657 & 192.913 \\
\hline & & & $\beta 21$ & 2365 & 106.707 & 78.742 & 85.610 & 326.275 \\
\hline & & 2 & $\beta 02$ & 2365 & 261.126 & 1804.890 & 5756781.519 & 6037516.906 \\
\hline & & & $\beta 12$ & 2365 & 18.374 & 4.302 & .480 & .365 \\
\hline & & & $\beta 22$ & 2365 & 4.259 & 6.818 & 1.387 & 1.320 \\
\hline
\end{tabular}




\section{Effect on $B_{0}$}

Consequently, in equation 1 , it can be inferred that the performances of the estimators are affected by autocorrelation under all criteria. The results of the LSD further test visa- vice their estimated marginal means revealed that all estimators except GLS2 are preferred to estimate $\beta_{0}$ at all the levels of autocorrelation.

In equation 2, the estimators are affected by autocorrelation and correlation between the error terms under all the criteria except in the bias criterion. The results of the LSD further test visa- vice their estimated marginal means revealed that all estimators except GLS2 are preferred for $\beta_{0}$ at all levels of autocorrelation and correlation between the error terms.

\section{Effect on $B_{1}$}

Consequently, in equation 1 , it can be inferred that the performances of the estimators are affected by autocorrelation under all criteria except for the bias. The results of the LSD further test visa- vice their estimated marginal means revealed that GLS2 and MLE estimators are preferred for $\beta_{1}$ at all the levels of autocorrelation.

In equation 2 , the estimators are affected by autocorrelation and correlation between the error terms under all the criteria except in the bias criterion. The results of the LSD further test visa- vice their estimated marginal means revealed that all estimators are preferred to get $\beta_{1}$ at all levels of autocorrelation and correlation between the error terms.

\section{Effect on $B_{2}$}

Consequently, in equation 1 , it can be inferred that the performances of the estimators are affected by autocorrelation and correlation between the error terms. The results of the LSD further test visa- vice their estimated marginal means revealed that GLS2 and MLE estimators are preferred to estimate $\beta_{2}$ at all the levels of autocorrelation.

In equation 2, the estimators are affected by autocorrelation and correlation between the error terms under all the criteria. The results of the LSD further test visavice their estimated marginal means revealed that SUR and 3SLS estimators are preferred to get $\beta_{2}$ at all levels of autocorrelation and correlation between the error terms EXCEPT for -0.9 and -0.8 correlation levels between the error terms under the bias that is significantly different.

Summarily, GLS2, MLE, SUR, and 3SLS are preferred to estimate the model at the sample size of 20. 
Table 2: ANOVA for the sample size of 30

\begin{tabular}{|c|c|c|c|c|c|c|c|c|}
\hline \multirow{2}{*}{ s. no. } & \multirow{2}{*}{ SOV } & \multirow{2}{*}{ EQN } & \multirow[b]{2}{*}{$\boldsymbol{\beta}_{\mathrm{i}}$} & \multirow{2}{*}{ df } & \multicolumn{4}{|c|}{ TYPE III SUM OF SQUARES } \\
\hline & & & & & Bias & Absolute Bias & Variance & Mean Square \\
\hline \multirow[t]{54}{*}{30} & \multirow[t]{6}{*}{$\mathrm{RE}$} & \multirow[t]{3}{*}{1} & $\beta 01$ & 12 & $1368.073^{\star \star \star}$ & $165272.612^{\star \star \star}$ & $1.008 \mathrm{E} 12^{\star \star \star}$ & $1.009 \mathrm{E} 12^{\star * *}$ \\
\hline & & & $\beta 11$ & 12 & $.029 * \star \star$ & $37.228^{\star * *}$ & $125.437^{\star \star \star}$ & $127.031^{\star \star \star}$ \\
\hline & & & $\beta 21$ & 12 & .075 & $29.385^{\star \star \star}$ & $69.897^{\star \star \star}$ & $83.604^{* * *}$ \\
\hline & & \multirow[t]{3}{*}{2} & $\beta 02$ & 12 & .095 & $51.854^{\star \star \star}$ & $6251392.175^{\star \star \star}$ & $6258276.131^{\star \star \star}$ \\
\hline & & & $\beta 12$ & 12 & .005 & $.334^{\star \star \star}$ & $.025^{\star \star \star}$ & $.025^{\star \star \star}$ \\
\hline & & & $\beta 22$ & 12 & .011 & $.175^{\star \star \star}$ & $.008 * * \star$ & $.043^{* \star \star}$ \\
\hline & \multirow[t]{6}{*}{ CR } & 1 & $\beta 01$ & 12 & .147 & 10.954 & 1.102E8 & $1.102 \mathrm{E} 8$ \\
\hline & & & $\beta 11$ & 12 & $271^{\star \star \star}$ & .043 & 144 & 137 \\
\hline & & & $\beta 21$ & 12 & $1.980^{\star \star \star}$ & $5.721^{\star \star \star}$ & $5.706^{\star \star \star}$ & $5.296^{\star \star \star}$ \\
\hline & & 2 & $\beta 02$ & 12 & .200 & $13.613^{\star \star \star}$ & $5187309.671^{\star \star \star}$ & $5192414.391^{\star \star \star}$ \\
\hline & & & $\beta 12$ & 12 & $2.338^{\star \star \star}$ & 012 & $.096^{\star \star \star}$ & .001 \\
\hline & & & $\beta 22$ & 12 & 695 & $15.467^{\star \star \star}$ & $.018^{\star \star \star}$ & $2.358^{\star \star \star}$ \\
\hline & \multirow[t]{6}{*}{ M } & 1 & $\beta 01$ & 6 & $187.891^{\star \star \star}$ & $82932.248^{\star \star \star}$ & 6.302E11 & $6.312 \mathrm{E} 11^{* \star \star}$ \\
\hline & & & $\beta 11$ & 6 & $.013^{* \star}$ & $5.296^{\star \star \star}$ & $7.289 * * \star$ & $7.403^{* * *}$ \\
\hline & & & $\beta 21$ & 6 & .009 & $4.316^{\star \star \star}$ & $8.386^{* * *}$ & $8.620^{\star * \star}$ \\
\hline & & 2 & $\beta 02$ & 6 & .007 & $9.955^{\star \star \star}$ & $5467535.629^{\star \star \star}$ & $5474905.799 * \star \star$ \\
\hline & & & $\beta 12$ & 6 & .029 & .034 & $.004^{\star * \star}$ & .004 \\
\hline & & & $\beta 22$ & 6 & .001 & $.114^{\star * *}$ & $.052^{\star \star \star}$ & $.040^{\star \star \star}$ \\
\hline & \multirow{6}{*}{$R E^{\star} \mathrm{CR}$} & & $\beta 01$ & 144 & 1.846 & 131.775 & $1.362 \mathrm{E} 9$ & $1.363 \mathrm{E} 9$ \\
\hline & & & $\beta 11$ & 144 & $143^{\star \star}$ & .163 & 1.140 & 1.113 \\
\hline & & & $\beta 21$ & 144 & 1.132 & $2.945^{\star * *}$ & $20.161^{\star \star \star}$ & $18.791^{\star \star \star}$ \\
\hline & & & $\beta 02$ & 144 & 1.196 & $70.924^{\star \star \star}$ & $3.657 \mathrm{E} 7^{\star \star \star \star}$ & $3.661 \mathrm{E} 7^{\star \star \star}$ \\
\hline & & & $\beta 12$ & 144 & .024 & .222 & $.016^{\star \star *}$ & .016 \\
\hline & & & $\beta 22$ & 144 & .034 & 108 & $.005^{\star \star \star}$ & 016 \\
\hline & \multirow[t]{6}{*}{$R E^{\star} M$} & 1 & $\beta 01$ & 72 & $7396.149^{\star \star \star}$ & $696530.165^{\star \star \star}$ & $6.041 \mathrm{E} 12^{\star \star \star}$ & $6.050 \mathrm{E} 12^{\star \star *}$ \\
\hline & & & $\beta 11$ & 72 & .012 & $17.083^{\star \star \star}$ & $51.754^{\star \star \star}$ & $52.348^{* \star *}$ \\
\hline & & & $\beta 21$ & 72 & .045 & $15.567^{\star \star \star}$ & $46.940 * * \star$ & $48.988^{* * \star}$ \\
\hline & & 2 & $\beta 02$ & 72 & 583 & $43.075^{\star \star \star}$ & 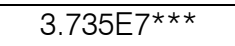 & $3.739 \mathrm{E} 7^{\star \star \star}$ \\
\hline & & & $\beta 12$ & 72 & .002 & .034 & $.003^{* \star}$ & .004 \\
\hline & & & $\beta 22$ & 72 & .028 & .105 & $.016^{\star * \star}$ & .026 \\
\hline & \multirow[t]{6}{*}{$\mathrm{CR}^{\star} \mathrm{M}$} & 1 & $\beta 01$ & 72 & .988 & 45.595 & $6.622 \mathrm{E} 8$ & $6.623 \mathrm{E} 8$ \\
\hline & & & $\beta 11$ & 72 & $203^{\star \star \star}$ & .032 & .108 & .103 \\
\hline & & & $\beta 21$ & 72 & $1.491^{* \star \star}$ & $4.279 * \star \star$ & 4.281 & 3.968 \\
\hline & & 2 & $\beta 02$ & 72 & .863 & $40.424^{\star \star \star}$ & $3.189 \mathrm{E} 7 * \star \star$ & $3.193 \mathrm{E} 7 * \star \star$ \\
\hline & & & $\beta 12$ & 72 & .012 & .085 & $.004^{\star * *}$ & .005 \\
\hline & & & $\beta 22$ & 72 & .009 & $.414^{\star \star *}$ & $.035^{\star \star \star}$ & .065 \\
\hline & \multirow{6}{*}{$\begin{array}{c}\mathrm{E}^{\star} \mathrm{CR} \\
\mathrm{M}\end{array}$} & 1 & $\beta 01$ & 864 & 10.321 & 546.890 & $8.173 \mathrm{E} 9$ & 8.174E9 \\
\hline & & & $\beta 11$ & 864 & .107 & .121 & .855 & .835 \\
\hline & & & $\beta 21$ & 864 & .853 & 2.202 & 15.134 & 14.102 \\
\hline & & 2 & $\beta 02$ & 864 & 7.135 & $249.877^{\star \star \star}$ & $2.190 \mathrm{E} 8^{\star \star \star}$ & $2.192 \mathrm{E} 8^{\star \star \star}$ \\
\hline & & & $\beta 12$ & 864 & .001 & 041 & .003 & .003 \\
\hline & & & $\beta 22$ & 864 & .014 & .174 & $.013^{* \star *}$ & .030 \\
\hline & \multirow[t]{6}{*}{ ERROR } & 1 & $\beta 01$ & 1183 & 3150.131 & 4943.259 & $4.933 \mathrm{E} 10$ & 5.003E10 \\
\hline & & & $\beta 11$ & 1183 & .916 & 19.633 & 110.203 & 112.032 \\
\hline & & & $\beta 21$ & 1183 & 13.579 & 13.356 & 69.548 & 66.923 \\
\hline & & 2 & $\beta 02$ & 1183 & 44.274 & 32.901 & $2.213 \mathrm{E} 7$ & $2.212 \mathrm{E} 7$ \\
\hline & & & $\beta 12$ & 1183 & 7.545 & 6.245 & .041 & .357 \\
\hline & & & $\beta 22$ & 1183 & 123.484 & 4.942 & 011 & 1.476 \\
\hline & TOTAL & 1 & $\beta 01$ & 2365 & 12115.647 & 950459.247 & 7.739E12 & $7.751 \mathrm{E} 12$ \\
\hline & & & $\beta 11$ & 2365 & 1.693 & 79.598 & 296.927 & 301.002 \\
\hline & & & $\beta 21$ & 2365 & 19.164 & 77.788 & 240.059 & 250.302 \\
\hline & & 2 & $\beta 02$ & 2365 & 54.357 & 512.744 & $3.639 \mathrm{E} 8$ & $3.642 \mathrm{E} 8$ \\
\hline & & & $\beta 12$ & 2365 & 9.965 & 7.003 & 192 & .413 \\
\hline & & & $\beta 22$ & 2365 & 124.277 & 21.562 & 158 & 4.059 \\
\hline
\end{tabular}




\section{Effect on $\beta_{0}$}

Consequently, in equation 1 , it can be inferred that the performances of the estimators are affected by autocorrelation under all criteria. The results of the LSD further test visa- vice their estimated marginal means revealed that all estimators are preferred to get $\beta_{0}$ at all the levels of autocorrelation except for GLS2, which differed significantly at $0.8,0.9$ and 0.99 autocorrelation levels.

In equation 2 , the estimators are affected by autocorrelation and correlation between the error terms under all the criteria except in the bias criterion. The results of the LSD further test visa- vice their estimated marginal means revealed that all estimators are preferred to get values for $\beta_{0}$ at all levels of autocorrelation and correlation between the error terms except for GLS2, which differed significantly at autocorrelation level of 0.9 and a correlation between the error terms of 0.99 under the bias criterion.

\section{Effect on $\beta_{1}$}

Consequently, in equation 1 , it can be inferred that the performances of the estimators are affected by autocorrelation and correlation between the error terms under all criteria. The results of the LSD further test visa- vice their estimated marginal means revealed that GLS2 and MLE estimators are preferred to calculate $\beta_{1}$ at all the levels of autocorrelation and correlation between the error terms.

In equation 2 , the estimators are affected by autocorrelation and correlation between the error terms under variance criterion. The results of the LSD further test visa- vice their estimated marginal means revealed that GLS2 and MLE estimators are preferred to get $\beta_{1}$ at all levels of autocorrelation and correlation between the error terms.

\section{Effect on $B_{2}$}

Consequently, in equation 1 , it can be inferred that the performances of the estimators are affected by autocorrelation and correlation between the error terms under all criteria. The results of the LSD further test visa- vice their estimated marginal means revealed that GLS2 and MLE estimators are preferred to estimate $\beta_{1}$ at all the levels of autocorrelation and correlation between the error terms except that we have to be cautious when using them at some levels of autocorrelation.

In equation 2 , the estimators are affected by autocorrelation and correlation between the error terms under variance criterion. The results of the LSD further test visa- vice their estimated marginal means revealed that all estimators except OLS, GLS2, and MLE estimators are preferred to calculate $\beta_{2}$ at all levels of autocorrelation and correlation between the error terms.

Summarily, GLS2 and MLE estimators are preferred to estimate the model at the sample size of 30 
Table 3: ANOVA for the sample size of 50

\begin{tabular}{|c|c|c|c|c|c|c|c|}
\hline \multirow{2}{*}{ s.no. } & \multirow{2}{*}{ SOV } & \multirow{2}{*}{$\boldsymbol{\beta}_{\mathrm{i}}$} & \multirow{2}{*}{ df } & \multicolumn{4}{|c|}{ TYPE III SUM OF SQUARES } \\
\hline & & & & Bias & Abs.Bias & Var & MSE \\
\hline \multirow[t]{54}{*}{50} & \multirow{6}{*}{$\mathrm{RE}$} & $\beta 01$ & 12 & $452.571^{\star \star \star}$ & 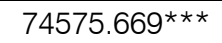 & $1.764 \mathrm{E} 11^{\star \star \star}$ & $1.770 \mathrm{E} 11^{\star \star \star}$ \\
\hline & & $\beta 11$ & 12 & $.050 * \star \star$ & $18.709 * \star \star$ & $24.791^{\star \star \star}$ & $24.976^{\star \star \star}$ \\
\hline & & $\beta 21$ & 12 & $1.014^{\star \star \star}$ & $6.985^{\star \star \star}$ & $1.255^{\star \star \star}$ & $2.662^{\star \star \star}$ \\
\hline & & $\beta 02$ & 12 & $.515^{\star \star \star}$ & $35.964^{\star \star *}$ & $251158.322^{\star \star *}$ & $252591.912^{\star * \star}$ \\
\hline & & $\beta 12$ & 12 & $.417^{\star \star \star}$ & $.167^{\star \star \star}$ & $.004^{\star \star \star}$ & $.007^{\star \star \star}$ \\
\hline & & $\beta 22$ & 12 & $.129^{\star *}$ & $.174^{\star \star \star}$ & $.001^{\star \star *}$ & $.003^{\star \star \star}$ \\
\hline & \multirow[t]{6}{*}{ CR } & $\beta 01$ & 12 & 1.992 & 234.178 & 1.404E9 & 1.406E9 \\
\hline & & $\beta 11$ & 12 & $.022^{\star \star \star}$ & $.972^{\star \star \star}$ & $1.780 * \star \star$ & $1.786^{\star \star \star}$ \\
\hline & & $\beta 21$ & 12 & $5.131^{\star \star \star}$ & $.177^{\star \star}$ & .052 & .030 \\
\hline & & $\beta 02$ & 12 & $1.353^{* * *}$ & $6.205^{\star \star \star}$ & $161713.711^{\star * *}$ & $162539.579 * \star *$ \\
\hline & & $\beta 12$ & 12 & $3.505^{\star * \star}$ & $1.093^{\star * *}$ & $.026 * \star \star$ & $.024^{\star \star \star}$ \\
\hline & & $\beta 22$ & 12 & $.221 * \star \star$ & $.373^{\star * *}$ & $.003^{\star \star \star}$ & $.003^{* \star *}$ \\
\hline & \multirow[t]{6}{*}{$\mathrm{M}$} & $\beta 01$ & 6 & $227.569^{\star \star \star}$ & $24107.884^{\star \star \star}$ & $8.971 \mathrm{E} 10^{\star \star \star}$ & $9.003 \mathrm{E} 10^{* * *}$ \\
\hline & & $\beta 11$ & 6 & .001 & $3.527^{\star \star \star}$ & $2.193^{* \star \star}$ & $2.209^{\star \star \star}$ \\
\hline & & $\beta 21$ & 6 & .085 & $2.311^{\star \star \star}$ & $.619 * \star \star$ & $.709 * \star \star$ \\
\hline & & $\beta 02$ & 6 & $.105^{\star * \star}$ & $1.285^{\star \star \star}$ & $178487.825^{\star \star \star}$ & $179459.300 * \star \star$ \\
\hline & & $\beta 12$ & 6 & $.021^{\star \star \star}$ & .003 & $.002^{\star * \star}$ & 8.218E-5 \\
\hline & & $\beta 22$ & 6 & .023 & $.307^{\star \star \star}$ & $.010^{\star \star \star}$ & $.012^{\star \star \star}$ \\
\hline & \multirow{6}{*}{$R E^{\star} \mathrm{CR}$} & $\beta 01$ & 144 & 23.036 & 2764.733 & 1.713E10 & $1.714 \mathrm{E} 10$ \\
\hline & & $\beta 11$ & 144 & .019 & $4.251^{\star \star \star}$ & $12.667^{\star \star \star}$ & $12.699 * * *$ \\
\hline & & $\beta 21$ & 144 & 1.698 & 1.158 & $.538^{\star \star \star}$ & $1.049 * \star \star$ \\
\hline & & $\beta 02$ & 144 & $2.520 * \star \star$ & $28.684^{\star \star \star}$ & $1365792.064^{\star \star \star}$ & $1373566.001^{* * *}$ \\
\hline & & $\beta 12$ & 144 & $.136^{\star \star \star}$ & $.165^{\star \star \star}$ & $.005^{\star \star \star}$ & .009 \\
\hline & & $\beta 22$ & 144 & .058 & .055 & .001 & .001 \\
\hline & \multirow[t]{6}{*}{$R E \star M$} & $\beta 01$ & 72 & $3285.331^{* \star \star}$ & $280727.544^{\star \star \star}$ & $1.056 \mathrm{E} 12^{\star \star \star}$ & $1.060 \mathrm{E} 12^{* \star *}$ \\
\hline & & $\beta 11$ & 72 & .021 & $8.107^{\star \star \star}$ & $10.064^{* \star \star}$ & 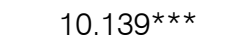 \\
\hline & & $\beta 21$ & 72 & .847 & $3.449 * * *$ & $1.724^{\star \star \star}$ & $1.696^{\star \star \star}$ \\
\hline & & $\beta 02$ & 72 & $2.363^{\star \star \star}$ & $10.635^{\star \star \star}$ & $1480512.907^{\star \star \star}$ & $1488990.865^{\star * *}$ \\
\hline & & $\beta 12$ & 72 & $.132^{\star \star \star}$ & $.218^{\star \star \star}$ & $.003^{\star \star \star}$ & $.008^{\star \star \star}$ \\
\hline & & $\beta 22$ & 72 & .009 & .064 & $.002^{\star \star \star}$ & .003 \\
\hline & \multirow[t]{6}{*}{$\mathrm{CR}^{\star} \mathrm{M}$} & $\beta 01$ & 72 & 11.459 & 1223.011 & $8.561 \mathrm{E} 9$ & $8.571 \mathrm{E} 9$ \\
\hline & & $\beta 11$ & 72 & .016 & .241 & .671 & .673 \\
\hline & & $\beta 21$ & 72 & $3.879 * * *$ & .469 & $.307^{\star \star \star}$ & .207 \\
\hline & & $\beta 02$ & 72 & $1.161^{\star \star \star}$ & $6.135^{\star \star \star}$ & $982226.051^{* * *}$ & $987452.884^{\star * *}$ \\
\hline & & $\beta 12$ & 72 & .012 & $.092^{\star * \star}$ & $.002^{\star \star}$ & $.007^{\star \star \star}$ \\
\hline & & $\beta 22$ & 72 & .010 & $276 * \star \star$ & $.006^{\star * *}$ & $.007^{\star * \star}$ \\
\hline & \multirow[t]{6}{*}{$\mathrm{RE}^{\star} \mathrm{CR}{ }^{\star} \mathrm{M}$} & $\beta 01$ & 864 & 137.160 & 14657.361 & $1.026 \mathrm{E} 11$ & 1.027E11 \\
\hline & & $\beta 11$ & 864 & .013 & 1.423 & 4.996 & 5.009 \\
\hline & & $\beta 21$ & 864 & 1.263 & .490 & 1.123 & .968 \\
\hline & & $\beta 02$ & 864 & $13.881^{* * *}$ & $59.010^{* \star \star}$ & $8150369.132^{\star \star \star}$ & $8196863.794^{* * *}$ \\
\hline & & $\beta 12$ & 864 & .048 & .067 & .002 & .003 \\
\hline & & $\beta 22$ & 864 & .008 & .050 & .002 & .002 \\
\hline & \multirow[t]{6}{*}{ ERROR } & $\beta 01$ & 1183 & 6296.390 & 82375.378 & 8.427E11 & $8.460 \mathrm{E} 11$ \\
\hline & & $\beta 11$ & 1183 & .278 & 8.667 & 23.218 & 23.233 \\
\hline & & $\beta 21$ & 1183 & 12.234 & 8.004 & 2.939 & 4.219 \\
\hline & & $\beta 02$ & 1183 & 4.175 & 9.073 & 1571334.088 & 1580748.512 \\
\hline & & $\beta 12$ & 1183 & .661 & .922 & .026 & .070 \\
\hline & & $\beta 22$ & 1183 & 6.136 & 1.510 & .012 & .043 \\
\hline & \multirow[t]{6}{*}{ TOTAL } & $\beta 01$ & 2365 & 10435.662 & 480676.871 & 2.295E12 & $2.303 \mathrm{E} 12$ \\
\hline & & $\beta 11$ & 2365 & .420 & 45.888 & 80.372 & 80.717 \\
\hline & & $\beta 21$ & 2365 & 26.153 & 23.042 & 8.557 & 11.540 \\
\hline & & $\beta 02$ & 2365 & 26.079 & 157.021 & 1.414E7 & 1.422E7 \\
\hline & & $\beta 12$ & 2365 & 4.946 & 2.729 & .070 & .128 \\
\hline & & $\beta 22$ & 2365 & 6.593 & 2.811 & .038 & .073 \\
\hline
\end{tabular}




\section{Effect on $\beta_{0}$}

Consequently, in equation 1 , it can be inferred that the performances of the estimators are affected by autocorrelation under all criteria. The results of the LSD further test visa- vice their estimated marginal means revealed that all estimators are preferred to estimate $\beta_{0}$ at all the levels of autocorrelation except for GLS2, which differed significantly at 0.99 autocorrelation level.

In equation 2, the estimators are affected by autocorrelation and correlation between the error terms under all the criteria. The results of the LSD further test visavice their estimated marginal means revealed that all estimators are preferred to compute $\beta_{0}$ at all levels of autocorrelation and correlation between the error terms except for GLS2 which differed significantly at autocorrelation levels of $0.9 \& 0.99$ and correlation between the error terms of 0.99 under all criteria.

\section{Effect on $\beta_{1}$}

Consequently, in equation 1 , it can be inferred that the performances of the estimators are affected by autocorrelation and correlation between the error terms under all criteria. The results of the LSD further test visa- vice their estimated marginal means revealed that GLS2 and MLE estimators are preferred to get $\beta_{1}$ at all the levels of autocorrelation and correlation between the error terms.

In equation 2, the estimators are affected by autocorrelation and correlation between the error terms under variance criterion. The results of the LSD further test visa- vice their estimated marginal means revealed that GLS2 and MLE estimators are preferred to compute $\beta_{1}$ at all levels of autocorrelation and correlation between the error terms.

\section{Effect on $\beta_{2}$}

Consequently, in equation 1 , it can be inferred that the performances of the estimators are affected by autocorrelation and correlation between the error terms. The results of the LSD further test visa- vice their estimated marginal means revealed that GLS2 and MLE estimators are preferred to estimate $\beta_{2}$ at all the levels of autocorrelation and correlation between the error terms.

In equation 2, the estimators are affected by autocorrelation and correlation between the error terms under all the criteria. The results of the LSD further test visavice their estimated marginal means revealed that all estimators except OLS, GLS2, and MLE estimators are preferred to get $\beta_{2}$ at all levels of autocorrelation and correlation between the error terms.

Summarily, GLS2 and MLE estimators are preferred to estimate the model at a sample size of 50 
Table 4: ANOVA for the sample size of 100

\begin{tabular}{|c|c|c|c|c|c|c|c|}
\hline \multirow{2}{*}{ s.no. } & \multirow{2}{*}{ SOV } & \multirow{2}{*}{$\boldsymbol{\beta}_{\mathrm{i}}$} & \multirow{2}{*}{$d f$} & \multicolumn{4}{|c|}{ TYPE III SUM OF SQUARES } \\
\hline & & & & Bias & Abs.Bias & Var & MSE \\
\hline \multirow[t]{54}{*}{100} & \multirow[t]{6}{*}{$\mathrm{RE}$} & $\beta 01$ & 12 & 47.699 & $48743.394^{\star \star \star}$ & 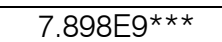 & $7.945 \mathrm{Eg}^{\star \star \star \star}$ \\
\hline & & $\beta 11$ & 12 & $.022^{\star \star \star}$ & $21.108^{\star * \star}$ & $33.739 * * *$ & $33.776^{\star \star *}$ \\
\hline & & $\beta 21$ & 12 & .014 & $7.287^{\star \star \star}$ & $3.435^{\star \star \star}$ & $4.171^{\star \star \star}$ \\
\hline & & $\beta 02$ & 12 & .031 & $23.608^{* * *}$ & $27762.719 * * *$ & $27802.782^{\star \star \star}$ \\
\hline & & $\beta 12$ & 12 & .004 & $.122^{\star \star \star}$ & $.002^{\star \star \star}$ & $.002^{\star \star \star}$ \\
\hline & & $\beta 22$ & 12 & .007 & $.019 * \star \star$ & $.001^{\star * *}$ & $.001 * \star \star *$ \\
\hline & \multirow[t]{6}{*}{$\mathrm{CR}$} & $\beta 01$ & 12 & .001 & .001 & .000 & .000 \\
\hline & & $\beta 11$ & 12 & $.011^{* * *}$ & .002 & .006 & .006 \\
\hline & & $\beta 21$ & 12 & $1.366^{\star * \star}$ & $1.539^{\star \star \star}$ & $.352^{\star \star \star}$ & $.320^{\star \star \star}$ \\
\hline & & $\beta 02$ & 12 & .486 & $.139 * \star \star$ & $12228.857^{\star \star \star}$ & $12185.714^{\star \star *}$ \\
\hline & & $\beta 12$ & 12 & $.047^{\star \star \star}$ & $.692^{\star \star \star}$ & $.018^{\star \star \star}$ & $.016^{\star \star \star}$ \\
\hline & & $\beta 22$ & 12 & .057 & $1.315^{\star \star \star}$ & $.002^{\star \star \star}$ & $.019 * \star \star$ \\
\hline & \multirow[t]{6}{*}{$\mathrm{M}$} & $\beta 01$ & 6 & 12.616 & $13036.510^{\star \star \star}$ & $3.909 \mathrm{E} 9 * \star \star$ & $3.932 \mathrm{E}^{\star \star \star \star}$ \\
\hline & & $\beta 11$ & 6 & $.005^{\star \star \star}$ & $3.739 * \star \star$ & $2.145^{\star \star \star}$ & $2.151^{\star \star \star}$ \\
\hline & & $\beta 21$ & 6 & .000 & $1.601^{* \star *}$ & $.568^{\star \star \star}$ & $.585^{\star \star \star}$ \\
\hline & & $\beta 02$ & 6 & .044 & $.218^{\star * *}$ & $13231.759 * * *$ & $13252.284^{* * *}$ \\
\hline & & $\beta 12$ & 6 & .003 & $.058^{\star * *}$ & $.002^{\star \star \star}$ & $.002^{\star \star \star}$ \\
\hline & & $\beta 22$ & 6 & .002 & $.095^{\star \star \star}$ & $.004^{\star * \star}$ & $.005^{\star \star \star}$ \\
\hline & \multirow{6}{*}{$\mathrm{RE}^{\star} \mathrm{CR}$} & $\beta 01$ & 144 & .001 & .008 & .002 & .002 \\
\hline & & $\beta 11$ & 144 & $.022 * \star \star$ & .026 & .077 & .077 \\
\hline & & $\beta 21$ & 144 & $.810^{\star \star \star}$ & $.784^{\star \star \star}$ & $1.083^{* * *}$ & $.978^{\star \star \star}$ \\
\hline & & $\beta 02$ & 144 & .204 & $15.466^{\star \star \star}$ & $147798.362^{\star \star *}$ & $148004.003^{* * *}$ \\
\hline & & $\beta 12$ & 144 & 011 & $.053^{\star \star \star}$ & $.002^{\star \star \star}$ & $.002^{\star \star \star}$ \\
\hline & & $\beta 22$ & 144 & .002 & .021 & $.000^{* * *}$ & .000 \\
\hline & \multirow[t]{6}{*}{$\mathrm{RE}^{*} \mathrm{M}$} & $\beta 01$ & 72 & 151.558 & $156345.485^{\star \star \star}$ & $4.691 \mathrm{E} 10^{* \star *}$ & $4.719 \mathrm{E} 10^{\star \star * \star}$ \\
\hline & & $\beta 11$ & 72 & $.015^{\star \star \star}$ & $9.522^{\star \star \star}$ & $13.766^{\star \star \star}$ & $13.781^{* * *}$ \\
\hline & & $\beta 21$ & 72 & .005 & $4.081^{* \star *}$ & $2.357^{\star \star \star}$ & $2.457^{\star \star \star}$ \\
\hline & & $\beta 02$ & 72 & 167 & $2.498^{* * \star}$ & $158513.192^{\star \star \star}$ & $158738.340^{* \star *}$ \\
\hline & & $\beta 12$ & 72 & .011 & $.044 * \star \star$ & $.001 * \star \star$ & $.001^{\star * *}$ \\
\hline & & $\beta 22$ & 72 & .009 & $.029 * * \star$ & $.001^{\star * *}$ & $.001^{* \star *}$ \\
\hline & \multirow[t]{6}{*}{$\mathrm{CR}^{\star} \mathrm{M}$} & $\beta 01$ & 72 & .001 & $7.294 \mathrm{E}-6$ & $5.759 \mathrm{E}-5$ & $6.569 \mathrm{E}-5$ \\
\hline & & $\beta 11$ & 72 & $.009^{\star \star \star}$ & .001 & .004 & .004 \\
\hline & & $\beta 21$ & 72 & $1.024 * * \star$ & $1.158^{* * \star}$ & $264^{\star * *}$ & $.240 * \star \star$ \\
\hline & & $\beta 02$ & 72 & .063 & $1.170^{\star \star \star \star}$ & $73197.801^{\star \star \star}$ & $73298.063^{\star \star \star}$ \\
\hline & & $\beta 12$ & 72 & .001 & $.052^{\star \star \star}$ & $.001^{\star \star \star}$ & $.001^{* \star *}$ \\
\hline & & $\beta 22$ & 72 & .002 & $.123^{\star \star *}$ & $.002^{* \star *}$ & $.002^{\star \star \star}$ \\
\hline & \multirow[t]{6}{*}{$\mathrm{RE}^{\star} \mathrm{CR}{ }^{\star} \mathrm{M}$} & $\beta 01$ & 864 & .001 & .000 & .001 & .001 \\
\hline & & $\beta 11$ & 864 & .018 & .016 & .058 & .057 \\
\hline & & $\beta 21$ & 864 & .610 & .587 & .813 & .734 \\
\hline & & $\beta 02$ & 864 & .899 & $13.854^{* * *}$ & $877548.891^{\star \star * *}$ & $878767.713^{\star \star *}$ \\
\hline & & $\beta 12$ & 864 & .011 & .029 & .001 & .001 \\
\hline & & $\beta 22$ & 864 & .005 & .038 & $.001^{\star * \star}$ & .001 \\
\hline & \multirow[t]{6}{*}{\begin{tabular}{|l|} 
ERROR \\
\end{tabular}} & $\beta 01$ & 1183 & 3458.358 & 1982.236 & 5.755E10 & $5.739 \mathrm{E} 10$ \\
\hline & & $\beta 11$ & 1183 & .034 & 8.157 & 27.089 & 27.121 \\
\hline & & $\beta 21$ & 1183 & 1.548 & 1.645 & 1.959 & 2.328 \\
\hline & & $\beta 02$ & 1183 & 28.879 & 4.729 & 142202.156 & 142616.134 \\
\hline & & $\beta 12$ & 1183 & .422 & .148 & .005 & .005 \\
\hline & & $\beta 22$ & 1183 & 13.178 & .257 & .000 & .009 \\
\hline & \multirow[t]{6}{*}{ TOTAL } & $\beta 01$ & 2365 & 3670.242 & 220115.863 & 1.163E11 & $1.165 \mathrm{E} 11$ \\
\hline & & $\beta 11$ & 2365 & .137 & 42.568 & 76.883 & 76.972 \\
\hline & & $\beta 21$ & 2365 & 5.378 & 18.685 & 10.833 & 11.814 \\
\hline & & $\beta 02$ & 2365 & 30.774 & 61.678 & 1452558.902 & 1454739.728 \\
\hline & & $\beta 12$ & 2365 & .510 & 1.199 & .031 & .030 \\
\hline & & $\beta 22$ & 2365 & 13.260 & 1.905 & .012 & .039 \\
\hline
\end{tabular}




\section{Effect on $\beta_{0}$}

Consequently, in equation 1 , it can be inferred that the performances of the estimators are affected by autocorrelation under absolute bias, variance, and mean square error criteria. The results of the LSD further test visa- vice their estimated marginal means revealed that all estimators are good to estimate $\beta_{0}$ at all the levels of autocorrelation except for GLS2 which differed significantly at 0.99 autocorrelation levels.

In equation 2, the estimators are affected by autocorrelation and correlation between the error terms under all the criteria. The results of the LSD further test visavice their estimated marginal means show that all estimators are good for the computation of $\beta_{0}$ at all levels of autocorrelation and correlation between the error terms except for GLS2, which differed significantly at autocorrelation level of 0.99 and correlation between the error terms of -0.99 and +0.99 under all the criteria considered.

\section{Effect on $\beta_{1}$}

Consequently, in equation 1 , it can be inferred that the performances of the estimators are affected by autocorrelation and correlation between the error terms under all criteria. The results of the LSD further test visa- vice their estimated marginal means revealed that GLS2 and MLE estimators are preferred to get $\beta_{1}$ at all the levels of autocorrelation and correlation between the error terms.

In equation 2, the estimators are affected by autocorrelation and correlation between the error terms under all the criteria. The results of the LSD further test visavice their estimated marginal means revealed that GLS2 and MLE estimators are preferred for the computation of $\beta_{1}$ at all levels of autocorrelation and correlation between the error terms.

\section{Effect on $\beta_{2}$}

Consequently, in equation 1 , it can be inferred that the performances of the estimators are affected by autocorrelation and correlation between the error terms under all criteria. The results of the LSD further test visa- vice their estimated marginal means revealed that GLS2 and MLE estimators are preferred to compute $\beta_{2}$ at all the levels of autocorrelation and correlation between the error terms. However, they too are significantly different at some limited levels of autocorrelation.

In equation 2, the estimators are affected by autocorrelation and correlation between the error terms under variance criterion. The results of the LSD further test visa- vice their estimated marginal means revealed that all estimators except OLS, GLS2, and MLE estimators are preferred to estimate $\beta_{2}$ at all levels of autocorrelation and correlation between the error terms.

Summarily, GLS2, SUR and MLE estimators are preferred to estimate the model at the sample size of 100 
Table 5: ANOVA for the sample size of 250

\begin{tabular}{|c|c|c|c|c|c|c|c|}
\hline \multirow{2}{*}{ s.no. } & \multirow{2}{*}{ SOV } & \multirow{2}{*}{$\boldsymbol{\beta}_{\mathrm{i}}$} & \multirow{2}{*}{$d f$} & \multicolumn{4}{|c|}{ TYPE III SUM OF SQUARES } \\
\hline & & & & Bias & Abs. Bias & Var & MSE \\
\hline \multirow[t]{54}{*}{250} & \multirow[t]{6}{*}{$\mathrm{RE}$} & $\beta 01$ & 12 & $1.478^{\star \star \star}$ & $4632.931 * \star \star$ & 1.059E8*** & $1.059 \mathrm{E} 8 * * *$ \\
\hline & & $\beta 11$ & 12 & 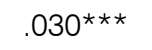 & $6.158^{\star \star \star}$ & $2.703^{\star \star \star}$ & $2.730 * \star \star$ \\
\hline & & $\beta 21$ & 12 & .001 & $2.812^{\star \star \star}$ & $.540^{\star \star \star}$ & $.658^{\star \star \star}$ \\
\hline & & $\beta 02$ & 12 & .003 & $6.709 * * \star$ & $83.297^{\star \star \star}$ & $83.466^{\star \star \star}$ \\
\hline & & $\beta 12$ & 12 & 319 & $.035^{\star \star \star}$ & 17.412 & $.001^{\star *}$ \\
\hline & & $\beta 22$ & 12 & .002 & $.021^{\star \star \star}$ & $8.986 \mathrm{E}-5^{\star \star \star \star}$ & $.000^{\star \star \star}$ \\
\hline & \multirow[t]{6}{*}{ CR } & $\beta 01$ & 12 & .008 & $6.104 \mathrm{E}-5$ & 8.877E-5 & $8.761 \mathrm{E}-5$ \\
\hline & & $\beta 11$ & 12 & .001 & $5.698 \mathrm{E}-5$ & $3.105 E-5$ & $3.798 \mathrm{E}-5$ \\
\hline & & $\beta 21$ & 12 & $205^{\star \star \star}$ & $.627^{\star \star \star}$ & $.062^{\star \star \star}$ & $.058^{\star \star \star}$ \\
\hline & & $\beta 02$ & 12 & $.338^{\star \star \star}$ & $.295^{\star \star \star}$ & 30.040 & 29.626 \\
\hline & & $\beta 12$ & 12 & $.778^{* \star}$ & $.356^{* * *}$ & 17.229 & $.006^{* * *}$ \\
\hline & & $\beta 22$ & 12 & .036 & $.303^{* * *}$ & $.000^{\star \star \star}$ & $.001 * * \star$ \\
\hline & \multirow[t]{6}{*}{$M$} & $\beta 01$ & 6 & $.190^{\star \star \star}$ & $873.346^{\star \star \star}$ & $5.133 \mathrm{E} 7^{\star \star \star}$ & $5.133 \mathrm{E} 7^{* \star *}$ \\
\hline & & $\beta 11$ & 6 & $7.732 E-5$ & $1.168^{\star \star \star}$ & $.229^{\star \star \star}$ & $.230^{\star \star \star}$ \\
\hline & & $\beta 21$ & 6 & .001 & $.583^{\star \star \star}$ & $.102^{\star \star \star}$ & $.105^{\star \star \star}$ \\
\hline & & $\beta 02$ & 6 & 001 & .021 & 28.674 & 28.775 \\
\hline & & $\beta 12$ & 6 & .182 & .007 & 8.763 & .000 \\
\hline & & $\beta 22$ & 6 & .001 & $.073^{\star \star \star}$ & $.001^{* \star \star}$ & $.001^{\star \star \star}$ \\
\hline & \multirow[t]{6}{*}{$\mathrm{RE}^{\star} \mathrm{CR}$} & $\beta 01$ & 144 & .005 & .000 & .001 & .001 \\
\hline & & $\beta 11$ & 144 & .012 & $9.808 \mathrm{E}-5$ & .000 & .000 \\
\hline & & $\beta 21$ & 144 & .176 & $.311 * \star$ & $.155^{\star \star \star}$ & $.148^{\star * *}$ \\
\hline & & $\beta 02$ & 144 & .027 & $2.815^{\star \star \star}$ & 352.222 & 353.150 \\
\hline & & $\beta 12$ & 144 & 3.609 & .015 & 209.071 & .000 \\
\hline & & $\beta 22$ & 144 & .005 & .012 & $6.516 \mathrm{E}-5^{\star \star \star *}$ & .000 \\
\hline & \multirow{6}{*}{$R E \star M$} & $\beta 01$ & 72 & 2.434 & $10508.921^{\star \star *}$ & $6.160 \mathrm{E} 8^{\star \star \star}$ & $6.161 \mathrm{E} 8^{* * *}$ \\
\hline & & $\beta 11$ & 72 & $.011^{\star \star \star}$ & $2.858^{\star \star \star}$ & $1.109 * \star \star$ & $1.120^{\star \star \star}$ \\
\hline & & $\beta 21$ & 72 & $.001^{\star \star \star}$ & $1.528^{\star * *}$ & $.355^{\star \star \star}$ & $.376^{\star \star \star}$ \\
\hline & & $\beta 02$ & 72 & .003 & .195 & $344.710^{\star \star \star}$ & $345.580^{* * *}$ \\
\hline & & $\beta 12$ & 72 & 1.811 & .071 & 104.517 & .001 \\
\hline & & $\beta 22$ & 72 & .002 & $.042^{\star \star *}$ & $.000^{\star \star \star}$ & $.000^{\star * *}$ \\
\hline & \multirow[t]{6}{*}{$C R^{\star} M$} & $\beta 01$ & 72 & .006 & $4.581 \mathrm{E}-5$ & $6.662 E-5$ & $6.574 \mathrm{E}-5$ \\
\hline & & $\beta 11$ & 72 & .001 & 3.947E-5 & 2.313E-5 & 2.817E-5 \\
\hline & & $\beta 21$ & 72 & $.152^{\star \star}$ & $.469^{\star \star \star}$ & .046 & .044 \\
\hline & & $\beta 02$ & 72 & .005 & .090 & 162.122 & 162.533 \\
\hline & & $\beta 12$ & 72 & 1.763 & .013 & 104.616 & .000 \\
\hline & & $\beta 22$ & 72 & .006 & $.075^{\text {** }}$ & $.001^{* \star *}$ & $.001^{\star * *}$ \\
\hline & \multirow{6}{*}{$\mathrm{RE}^{\star} \mathrm{CR}{ }^{\star} \mathrm{M}$} & $\beta 01$ & 864 & .004 & .000 & .001 & .001 \\
\hline & & $\beta 11$ & 864 & .009 & 8.591E-5 & .000 & .000 \\
\hline & & $\beta 21$ & 864 & .131 & .233 & .116 & .111 \\
\hline & & $\beta 02$ & 864 & .055 & 1.121 & 1945.383 & 1950.633 \\
\hline & & $\beta 12$ & 864 & 21.396 & .030 & 1254.431 & .001 \\
\hline & & $\beta 22$ & 864 & .004 & .021 & $.000 * \star \star$ & .000 \\
\hline & \multirow[t]{6}{*}{ ERROR } & $\beta 01$ & 1183 & 3.854 & 16061.289 & $7.821 \mathrm{E} 8$ & $7.822 \mathrm{E} 8$ \\
\hline & & $\beta 11$ & 1183 & .082 & 3.122 & 2.240 & 2.268 \\
\hline & & $\beta 21$ & 1183 & 1.781 & 2.054 & .749 & .792 \\
\hline & & $\beta 02$ & 1183 & 3.320 & 7.305 & 2945.654 & 2953.427 \\
\hline & & $\beta 12$ & 1183 & 37.560 & 1.475 & 1717.611 & .034 \\
\hline & & $\beta 22$ & 1183 & 3.873 & .314 & $6.234 \mathrm{E}-5$ & .003 \\
\hline & \multirow{6}{*}{ TOTAL } & $\beta 01$ & 2365 & 7.981 & 32077.122 & 1.555E9 & 1.556E9 \\
\hline & & $\beta 11$ & 2365 & .146 & 13.305 & 6.281 & 6.348 \\
\hline & & $\beta 21$ & 2365 & 2.449 & 8.618 & 2.125 & 2.292 \\
\hline & & $\beta 02$ & 2365 & 3.756 & 18.552 & 5892.407 & 5907.490 \\
\hline & & $\beta 12$ & 2365 & 67.419 & 2.003 & 3433.660 & .042 \\
\hline & & $\beta 22$ & 2365 & 3.929 & .863 & .003 & .007 \\
\hline
\end{tabular}




\section{Effect on $\beta_{0}$}

Consequently, in equation 1 , it can be inferred that the performances of the estimators are affected by autocorrelation under all criteria. The results of the LSD further test visa- vice their estimated marginal means revealed that all estimators are preferred to estimate $\beta_{0}$ at all the levels of autocorrelation except for GLS2, which differed significantly at 0.99 autocorrelation levels.

In equation 2, the estimators are affected by autocorrelation under variance and mean square error criteria. The results of the LSD further test visa- vice their estimated marginal means revealed that all estimators are preferred to compute $\beta_{0}$ at all levels of autocorrelation except for GLS2, which differed significantly at autocorrelation level of 0.99 in both criteria considered.

Summarily, we can infer that all the estimators are preferred to estimate $\beta_{0}$ except GLS2 at all the five sample sizes under consideration.

\section{Effect on $\beta_{1}$}

Consequently, in equation 1 , it can be inferred that the performances of the estimators are affected by autocorrelation under all criteria. The results of the LSD further test visa- vice their estimated marginal means revealed that GLS2 and MLE estimators are preferred to estimate $\beta_{1}$ at all the levels of autocorrelation.

In equation 2 , the estimators are neither affected by autocorrelation nor correlation between the error terms under all criteria.

Summarily, we can infer that GLS2 and MLE estimators are preferred to estimate $\beta_{1}$ at all five sample sizes under consideration and at all levels of autocorrelation and correlation between the error terms.

\section{Effect on $\beta_{2}$}

Consequently, in equation 1, it can be inferred that the performances of the estimators are affected by autocorrelation and correlation between the error terms under all the criteria. The results of the LSD further test visa- vice their estimated marginal means revealed that GLS2 and MLE estimators are preferred to get values for $\beta_{2}$ at all the levels, except at -0.99 and +0.99 levels for correlation between the error terms under absolute bias.

In equation 2, the estimators are affected by autocorrelation and correlation between the error terms under variance criterion. The results of the LSD further test visa- vice their estimated marginal means revealed that all estimators except OLS, GLS2, and MLE estimators are preferred to estimate $\beta_{2}$ at all the levels of autocorrelation and correlation between the error terms. We can now infer that GLS2 and MLE estimators are preferred to estimate $\beta_{2}$.

Summarily, MLE estimator is the most preferred for the model at the sample size of 250

Conclusively, MLE is the most preferred to estimate all the parameters of the model in the presence of correlation between the error terms and autocorrelation at the entire five different sample sizes. 


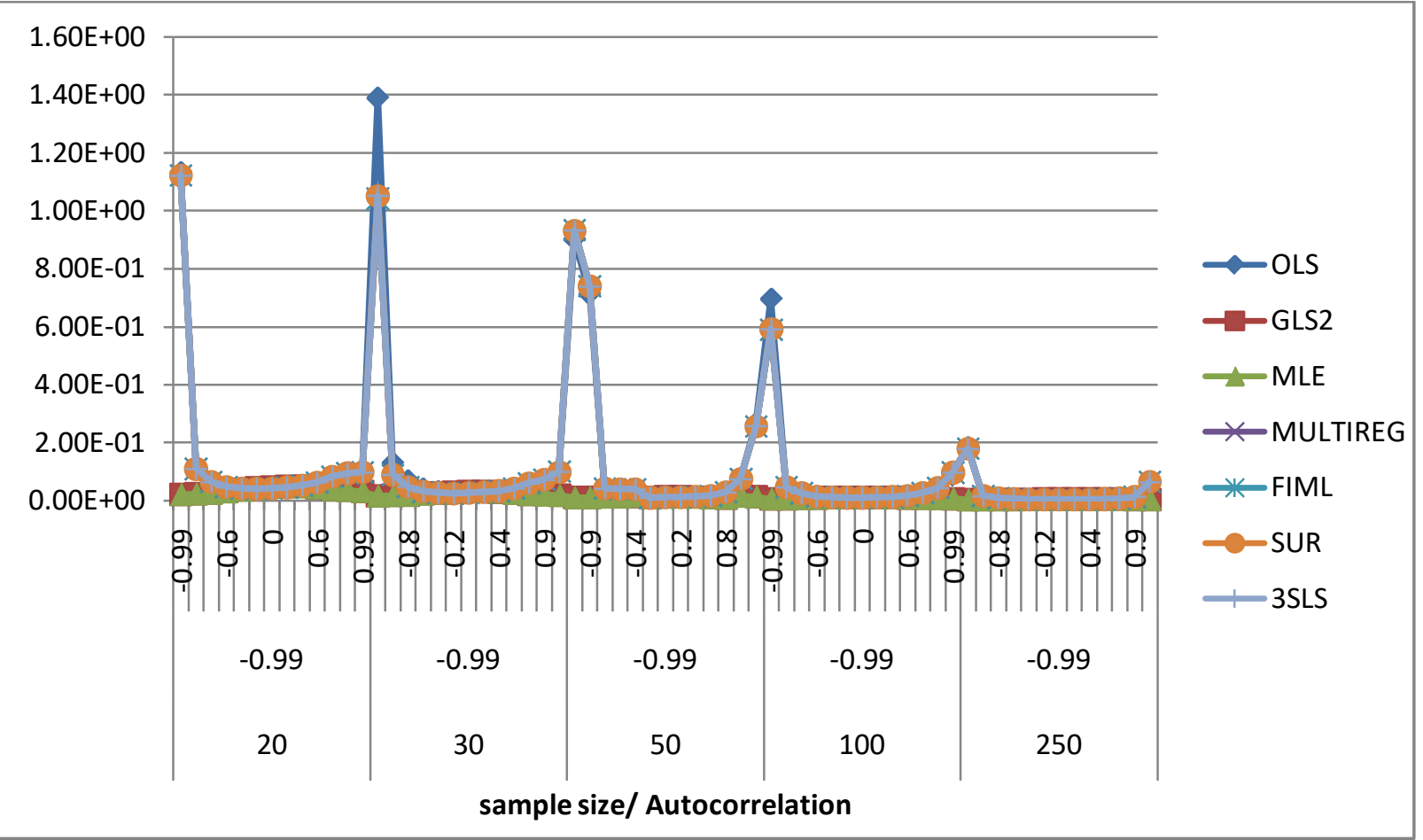

Figure 1: Performaces of the estimators using $\operatorname{MSE}\left(\mathrm{B}_{11}\right)$ at different levels of sample size, correlation bet the error term and autocorrelation at $\mathrm{CR}=-0.99$

In figure 1, the plot of MSE values against different sample sizes for all the estimators revealed an appreciable increase in efficiency (lower MSE) of the estimators as sample size increases with MLE estimator showing a better performance over GLS2.

\section{Summary of the Findings}

\section{a) When there is a correlation between the error terms and Autocorrelation}

The summary of results from the analysis of variance tables of the criteria showing the performances of the estimators and sample sizes on parameters of the two equations model when there is the presence of correlation between the error terms and autocorrelation are given in Table 6 below: 
Table 6: Summary of results when there is a correlation between the error terms and in the presence of autocorrelation

\begin{tabular}{|c|c|c|c|c|c|}
\hline s. no. & Eq. no. & Parameters & Preferred & Overall Assessment & Most Preferred \\
\hline \multirow[t]{6}{*}{20} & \multirow[t]{3}{*}{1} & $\beta_{01}$ & All except CORC & \multirow[t]{3}{*}{ CORC, MLE } & \multirow[t]{6}{*}{ MLE } \\
\hline & & $\beta_{11}$ & CORC, MLE & & \\
\hline & & $\beta_{21}$ & CORC, MLE & & \\
\hline & \multirow[t]{3}{*}{2} & $\beta_{02}$ & All except CORC & \multirow[t]{3}{*}{ All except CORC } & \\
\hline & & $\beta_{12}$ & All & & \\
\hline & & $\beta_{22}$ & SUR, 3SLS & & \\
\hline \multirow[t]{6}{*}{30} & \multirow[t]{3}{*}{1} & $\beta_{01}$ & All except CORC & \multirow[t]{3}{*}{ CORC, MLE } & \multirow[t]{6}{*}{ MLE } \\
\hline & & $\beta_{11}$ & CORC, MLE & & \\
\hline & & $\beta_{21}$ & CORC, MLE & & \\
\hline & \multirow[t]{3}{*}{2} & $\beta_{02}$ & All except CORC & \multirow[t]{3}{*}{ MLE.SUR,3SLS } & \\
\hline & & $\beta_{12}$ & CORC, MLE & & \\
\hline & & $\beta_{22}$ & MulReg,FIML,SUR,3SLS & & \\
\hline \multirow[t]{6}{*}{50} & \multirow[t]{3}{*}{1} & $\beta_{01}$ & All & \multirow[t]{3}{*}{ CORC, MLE } & \multirow[t]{6}{*}{ CORC, MLE } \\
\hline & & $\beta_{11}$ & CORC, MLE & & \\
\hline & & $\beta_{21}$ & CORC, MLE & & \\
\hline & \multirow[t]{3}{*}{2} & $\beta_{02}$ & All & \multirow[t]{3}{*}{ CORC,MLE.SUR,3SLS } & \\
\hline & & $\beta_{12}$ & CORC, MLE & & \\
\hline & & $\beta_{22}$ & MulReg,FIML,SUR,3SLS & & \\
\hline \multirow[t]{6}{*}{100} & \multirow[t]{3}{*}{1} & $\beta_{01}$ & All except CORC & \multirow[t]{3}{*}{ CORC, MLE } & \multirow[t]{6}{*}{ MLE } \\
\hline & & $\beta_{11}$ & CORC, MLE & & \\
\hline & & $\beta_{21}$ & CORC, MLE & & \\
\hline & \multirow[t]{3}{*}{2} & $\beta_{02}$ & All except CORC & \multirow{3}{*}{$\begin{array}{c}\text { MLE,MulReg,FIML,SUR } \\
\text {,3SLS }\end{array}$} & \\
\hline & & $\beta_{12}$ & CORC, MLE & & \\
\hline & & $\beta_{22}$ & MulReg,FIML,SUR,3SLS & & \\
\hline \multirow[t]{6}{*}{250} & \multirow[t]{3}{*}{1} & $\beta_{01}$ & All except CORC & \multirow[t]{3}{*}{ CORC, MLE } & \multirow[t]{6}{*}{ MLE } \\
\hline & & $\beta_{11}$ & CORC, MLE & & \\
\hline & & $\beta_{21}$ & CORC, MLE & & \\
\hline & \multirow[t]{3}{*}{2} & $\beta_{02}$ & All except CORC & \multirow[t]{3}{*}{ All except CORC } & \\
\hline & & $\beta_{12}$ & All & & \\
\hline & & $\beta_{22}$ & MulReg, FIML,SUR, 3SLS & & \\
\hline
\end{tabular}

From table 6 when there is the presence of correlation between the error terms and autocorrelation in the model under the equation 1 in all the five sample sizes, all the estimating methods except CORC are equally good in estimating the parameter $\beta_{01}$, meanwhile, for parameters $\beta_{11}$ and $\beta_{21}$ CORC and MLE estimators are preferred, thus, it can be concluded that MLE estimating method can be used in estimating all the model parameters in equation 1.

Under equation 2, it was observed that all estimation methods except CORC can be used in estimating all the parameters of the model at all levels of the sample sizes.

However, observing the two equations together, we can conclude that MLE is the most preferred in estimating all the parameters of the two equations among all the estimation methods used.

\section{RECOMMENDATION}

The research work has revealed that the MLE method of estimation is the most preferred estimator in estimating all the parameters of the model based on the four criteria used, namely, Bias, Absolute Bias, Variance, and Mean Square Error under the five-level of sample sizes considered. It can, therefore, be recommended that when the validity of correlation assumptions considered cannot be authenticated in a system of regression equation, the most preferred estimator to use is MLE. 


\section{References Références Referencias}

1. Aitken, A.C. (1935). On Least Squares and Linear Combinations of observations. Proceedings of the Royal Statistical Society. Edinburgh, 55, 42-48.

2. Ayinde K. and Oyejola B.A. (2007): A comparative Study of the Performances of the OLS and Some GLS Estimators when Stochastic Regressors are correlated with the error terms. Research Journal of Applied Sciences. 2 (3):215-220. Published by Medwell Journals, Faisalabad, Pakistan.

3. Chipman, J.S. (1979). Efficiency of Least Squares Estimation of linear Trend when residuals are auto correlated. ECTRA, 47,115-127.

4. David Edgerton \& Ghazi Shukur (1999) Testing autocorrelation in a system perspective testing autocorrelation, Econometric Reviews, 18:4, 343-386, DOI: 10.1080/07474939908800351

5. Fomby, B.T.; Carter, R.H. and Johnson, R.S. (1988): Advanced Econometric Methods. Springer-Verlag, New York.

6. GreenW.(2003). Econometric Analysis (5 $5^{\text {th }}$ Edition). New York Macmillan. Pearson Education Inc. USA.

7. Kleiber, C. (2001). Finite Sample Efficiency of OLS in Linear Regression Models with Long - Memory Disturbances. Economics Letters, 72, 131-136.

8. Kramer W. (1980). Finite Sample Efficiency of Ordinary Least Squares in the Linear Regression Model with Auto correlated Errors. JASA, 81,150-154.

9. Nwabueze, J.C. (2000). Estimation of Parameters of Linear Regression Models with Auto correlated Errors terms. Unpublished Ph.D Thesis. University of Ibadan, Nigeria.

10. O'Donnell, C.J.; Shumway, C.R. \& Ball, V.E. (1999). Input demands and inefficiency in US agriculture. American Journal of Agricultural Economics. 81:865880.

11. Olanrewaju S.O. (2013). Effects of Multicollinearity, Autocorrelation, and Correlation between the error terms on some Estimators in a System of Regression Equation. Unpublished PhD Thesis submitted to the Department of Statistics, University of Ilorin, Ilorin. Kwara State Nigeria.

12. Olanrewaju S.O.; Yahaya H.Uand Nasiru M.O. (2017) -Effects of Multicollinearity and Autocorrelation on Some Estimators in a System of Regression Equation. European Journal of Statistics and Probability. Vol.5(3), Pg 1-15.

13. Powell, A. A., (1965), Aitken Estimators as a tool in Allocating Predetermined Aggregates. Journal of the American Statistical Association. 64: 913 - 922.

14. Srivasta, V. K. \& Giles D. E. A.(1987). SURE equations model: Estimation and inference, New York: Marcel Dekker.

15. Unger, D.A., H. van den Dool, E. O'Lenic, and D. Collins, (2009): Ensemble Regression. Mon. Wea. Rev., 137, 2365-2379, https://doi.org/10.1175/2008 MWR2605.1

16. Wilde, P.E.; McNamara P.E.\& Ranney, C.K. (1999). The effect of income and food programs on dietry quality: A seemingly unrelated regression analysis with error components. Amer. J. of Agric. Economics 81(4):959-971.

17. Zellner, A. (1962). An efficient method of estimating seemingly unrelated regression equations and test for aggregation bias. J. Amer. Statist. Asso.57:348-368.

18. Zellner, A. (1963). Estimators for seemingly unrelated regression equations: Some exact finite sample results J. Amer. Statist. Asso.58:977-992. 